\title{
Measurement of pulmonary status and surfactant protein levels during dexamethasone treatment of neonatal respiratory distress syndrome
}

Jiu-Yao Wang, ^ Tsu-Fuh Yeh, Yu-Chih Lin, Kazuo Miyamura, Uffe Holmskov, Kenneth B $M$ Reid

\begin{abstract}
Background - Early postnatal use of dexamethasone in infants with respiratory distress syndrome (RDS) has been shown effectively to improve pulmonary status and to allow early weaning off mechanical ventilation. However, the mechanisms to explain the beneficial effects of dexamethasone in ventilatory dependent preterm infants remain unclear.

Methods - A double blind, placebo controlled study was performed to determine the change in pulmonary ventilation of premature infants with $R D S$ as a result of dexamethasone treatment, and to evaluate the effect of dexamethasone on the levels of surfactant-associated proteins A (SP-A) and D (SP-D) in the tracheal fluid from 34 premature infants with RDS and 29 control subjects.
\end{abstract}

Results - Dexamethasone treatment decreased fractional inspired oxygen concentration $\left(\mathrm{FIO}_{2}\right)$, arterial carbon dioxide tension $\left(\mathrm{PCO}_{2}\right)$, mean airway pressure (MAP), and facilitated successful weaning from mechanical ventilation. SP-A concentrations in the tracheal aspirates were increased at days 7 and 14, and SP-D concentrations were increased during the period from days 3 to 14 in the dexamethasone treated group compared with the control group. However, albumin levels in the tracheal aspirate samples were decreased after dexamethasone treatment over the period from days 3 to 14 . There was an inverse correlation between $\mathrm{PCO}_{2}$ values and SP-A concentrations.

Conclusions - These result suggest that early use of dexamethasone can improve pulmonary status and also increase SP-A and SP-D levels in the tracheal fluid in premature infants with RDS.

(Thorax 1996;51:907-913)

Keywords: respiratory distress syndrome (RDS), surfactant proteins A and D (SP-A and SP-D), dexamethasone, tracheal aspirates, bronchopulmonary dysplasia.

Correspondence to: Dr J-Y Wang.

^Current address: MRC Immunochemistry Unit Department of Biochemistry University of Oxford, Oxford OX1 3QU, UK

Received 30 August 1995 Returned to authors 24 November 1995 Revised version received 9 February 1996 Accepted for publication 28 February 1996

important cause of mortality and morbidity premature infants. The pathogenesis of RDS is related in part to the lack of pulmonary surfactant, a complex mixture of phospholipids and lung-specific proteins which are secreted by alveolar type II cells and reduce surface ten-
Pulmonary surfactant consists of about $90 \%$ lipid (mainly phospholipids) and 5-10\% surfactant-specific proteins (SP). Although phospholipids are critical for the generation of low surface pressures, four specific surfactant proteins (SP-A, B, C, and D) have been identified that appear to be more important in mediating surfactant function and metabolism. ${ }^{2-4}$

It has been shown that adequate concentrations of SP-A may be critical for full biophysical function of the surfactant complex and may play a major part in the organisation of phospholipids into tubular myelin, ${ }^{5}$ as well as in the regulation of phospholipid secretion and re-uptake. ${ }^{6}$ SP-D has recently been identified and isolated from human amniotic fluid and bronchoalveolar lavage. ${ }^{78}$ Both SP-A and SP-D can interact with lipopolysaccharides from Gram negative bacteria, facilitate opsonisation, and enhance the respiratory burst of alveolar macrophages. ${ }^{9-11}$ Therefore, they also contribute to the innate immunity that may play an important part in the first line defence in the developing lung of premature and newborn infants. ${ }^{12}$

Corticosteroids, with their antiinflammatory and cell regulatory functions, have been administered for the treatment of many inflammatory and fibrotic lung diseases including bronchopulmonary dysplasia. ${ }^{13}{ }^{14} \mathrm{We}$ have previously shown that administration of dexamethasone to premature infants with severe RDS shortly after birth and during the first 12 postnatal days improved pulmonary compliance and facilitated weaning from mechanical ventilation. ${ }^{15}$ Early use of dexamethasone may also prevent or minimise lung injuries associated with mechanical ventilation and oxygen therapy. ${ }^{16}$ Although it has been shown that glucocorticoids may enhance SP-A and SP-D synthesis in vitro and in animal fetal lung, ${ }^{17-19}$ less is known about SP-A and SP-D in the airways of preterm neonates, with or without RDS, and in those receiving dexamethasone treatment.

We have performed a randomised, double blind, placebo controlled trial on 63 preterm neonates with RDS to evaluate the effect of dexamethasone treatment on the changes of SP-A and SP-D levels in the tracheal fluid and to establish whether these changes correlated with pulmonary outcome. sion at the air-liquid interface in the alveolus. ${ }^{1}$

\section{Methods}

SUBJECT SELECTION

The protocol used in this study was approved by the human research and ethics committee of 
the hospital and informed consent was obtained from parents in each case. During the one year period between October 1992 and September 1993 all infants whose birth weights ranged from 1000 to $1999 \mathrm{~g}$ (appropriate size for gestational age) with a clinical and chest radiographic picture consistent. with severe RDS who required mechanical ventilation shortly after birth (0-12 hours postnatal age) were considered for inclusion in the study. Inclusion criteria and the diagnosis of RDS were made according to clinical and radiological features previously reported. ${ }^{15}$ Exclusion criteria at entry included a strong suspicion of sepsis or pneumonia - that is, chest radiographic findings not consistent with RDS, cardiovascular instability, meconium aspiration syndrome - and congenital heart diseases. Most of the very low birth weight infants $(<1000 \mathrm{~g})$ were not eligible for inclusion in the study because of the high incidence of early onset of sepsis (20 out of 23 infants). After a 24 hour period of initial stabilisation, infants who met the inclusion criteria were randomly assigned to receive a 21 day course of either $0.9 \%$ saline placebo or dexamethasone sodium phosphate in a double blind fashion. The dosages were administered according to the following schedule (one dose every 12 hours): days $1-7,0.25 \mathrm{mg} / \mathrm{kg}$; days $8-14,0.125 \mathrm{mg} / \mathrm{kg}$; days $15-21,0.05 \mathrm{mg} / \mathrm{kg}$. The first dose of dexamethasone was administered during the first 12 hours after birth.

None of the infants received exogenous surfactant since it was not commercially available in Taiwan at the time of the study. For all infants supplemental oxygen and mechanical ventilation were adjusted to maintain the arterial oxygen tension between 6.5 and $9.1 \mathrm{kPa}$ (50-70 $\mathrm{mm} \mathrm{Hg}$ ) or an oxygen saturation of haemoglobin of $88-92 \%$, and arterial carbon dioxide tension between 5.4 and $7.8 \mathrm{kPa}$ (40-60 $\mathrm{mm} \mathrm{Hg}$ ). Ventilatory support was provided with a pressure limited ventilator. Pulmonary outcome was evaluated at 28 days of age. Bronchopulmonary dysplasia was defined as the requirement for mechanical ventilation and supplemental oxygen at 28 days after birth in association with radiographic abnormalities compatible with this diagnosis. Because of the potential risk of infections associated with steroid therapy, all infants were given ampicillin and gentamicin for seven days. Subsequent use of antibiotics was determined individually by the attending physician. No methylxanthines or diuretics were administered during the study or at any time before or after extubation.

\section{SAMPLING TECHNIQUE}

Samples for measurement of SP-A and SP-D concentrations were obtained from tracheal aspirate specimens at the time of routine suctioning for pulmonary toilet in the following manner. Normal saline, $0.5-1.0 \mathrm{ml}$, was instilled into the endotracheal tube and 5-10 breaths were made by assisted ventilation. Following chest percussion and vibration, a sterile suction catheter was inserted into the endotracheal tube and gentle suction was performed.
The aspirated fluid was thoroughly agitated in $2.0 \mathrm{ml}$ normal saline, centrifuged at $1000 \mathrm{~g}$ for 10 minutes, and the supernatant was frozen at $-70^{\circ} \mathrm{C}$ until assayed. Aspirates were obtained before the study and on days 1, 3, 7, and 14 after treatment, or discontinued when the patients were weaned from mechanical ventilation.

PURIFICATION OF HUMAN SP-A, SP-D, AND PREPARATION OF ANTISERUM

The preparation methods for purified human SP-A and SP-D have been reported elsewhere. ${ }^{20}$ In brief, human SP-A and SP-D were purified from a pool of bronchoalveolar lavage fluid in patients with alveolar proteinosis by a procedure involving two steps of lectin affinity chromatography followed by gel filtration on Superose $6 .^{8}$

MEASUREMENT OF SP-D, SP-A, AND ALBUMIN IN TRACHEAL FLUID

For measurement of human SP-D in samples of tracheal aspirates a sandwich ELISA method using rabbit anti-human SP-D polyclonal antibody was used as previously described. ${ }^{20}$ In brief, the microtitre plate (Limbro, ICN Biomedicals Ltd, High Wycombe, Bucks, UK) was coated with rabbit antihuman SP-D IgG $(10 \mu \mathrm{g} / \mathrm{ml}$ in $35 \mu \mathrm{mM}$ $\mathrm{Na}_{2} \mathrm{CO}_{3}, \mathrm{pH} 9.6$ ) at $4^{\circ} \mathrm{C}$ overnight and the non-specific binding sites were blocked with TBS-NTC ( $50 \mathrm{mM}$ Tris, $50 \mathrm{mM} \mathrm{NaCl}, 2 \mathrm{mM}$ $\mathrm{CaCl}_{2}, 0.05 \%$ (v/v) Tween-20, 0.05\% (w/v) $\mathrm{NaN}_{3}, \mathrm{pH} 7.4$ ) containing $1 \mathrm{mg} / \mathrm{ml} \mathrm{BSA}$ for one hour at $37^{\circ} \mathrm{C}$. Purified human SP-D (5-50 $\mathrm{ng} / \mathrm{ml}$ ) to be used as a standard and aliquots of tracheal aspirate samples were duplicated in four serial dilutions in TBS-NTC buffer. The final amount of SP-D was calculated using these four dilutions. After extensive washes of the wells with TBS-NTC buffer, the samples $(100 \mu \mathrm{l})$ and standards were added to each well and incubated for three hours at $37^{\circ} \mathrm{C}$. The unbound fraction was removed by a series of washes with buffer. The plates were then incubated with biotinylated anti-human SP-D IgG $(50 \mu \mathrm{g} / \mathrm{ml}, 100 \mu \mathrm{l} /$ well $)$ for two hours at $37^{\circ} \mathrm{C}$. Finally, streptavidin-alkaline phosphatase conjugate (Sigma Chemical Co Ltd, Poole, Dorset, UK) diluted 1:10000 in TBS-NTC containing $1 \mathrm{mg} / \mathrm{ml}$ BSA was added and allowed to bind for one hour at room temperature. After washing the plate with TBS-NTC buffer, $p$-nitrophenyl phosphate (Sigma) was used as a substrate for the phosphatase reaction and incubated for 30 minutes at $37^{\circ} \mathrm{C}$. The reaction was stopped by addition of $1 \mathrm{~N}$ $\mathrm{NaOH}$ and the plate was read at $405 \mathrm{~nm}$.

SP-A levels in tracheal aspirate samples were measured using a similar ELISA method to the immunoassay for SP-D. Polyclonal anti-human SP-A antibodies were prepared in chickens and New Zealand rabbits by repeated injection of approximately $1 \mathrm{mg}$ purified human SP-A in Freund's complete adjuvant. The chicken and rabbit antisera were then used as the first and second antibodies in a capture ELISA as described above. Each assay plate included a standard curve generated with purified human 
Table 1 Mean (SD) clinical and laboratory characteristics in the perinatal period

\begin{tabular}{|c|c|c|c|c|}
\hline \multirow[b]{2}{*}{ Birth weight $(g)$} & \multicolumn{2}{|c|}{$\begin{array}{l}\text { Placebo group } \\
(n=29)\end{array}$} & \multicolumn{2}{|c|}{$\begin{array}{l}\text { Dexamethasone } \\
\text { group }(n=34)\end{array}$} \\
\hline & 1378 & $(344)$ & 1392 & (237) \\
\hline Gestational age (weeks) & 29 & $(2.9)$ & 28 & $(2.7)$ \\
\hline $\operatorname{Sex}(M / F)$ & $17 / 12$ & & $16 / 18$ & \\
\hline Median (range) Apgar score at $1 \mathrm{~min}$ & 4 & $(1-7)$ & 4 & $(2-7)$ \\
\hline Median (range) Apgar score at $5 \mathrm{~min}$ & 6 & $(4-8)$ & 6 & $(3-8)$ \\
\hline $\begin{array}{l}\% \text { of mothers in whom antenatal } \\
\text { glucocorticoids were used }\end{array}$ & $56 \%$ & & $50 \%$ & \\
\hline $\begin{array}{l}\text { Postnatal age at the time of first dose of } \\
\text { treatment (hours) }\end{array}$ & 8.9 & $(1.6)$ & 9.2 & $(1.4)$ \\
\hline $\mathrm{FIO}_{2}$ & 0.5 & $(0.24)$ & 0.5 & $(0.28)$ \\
\hline $\mathrm{Po}_{2}(\mathrm{kPa})$ & 11.5 & $(3.3)$ & 12.8 & $(3.7)$ \\
\hline $\mathrm{PCO}_{2}(\mathrm{kPa})$ & 5.6 & $(2.1)$ & 5.9 & $(2.4)$ \\
\hline $\mathrm{pH}$ & 7.3 & $(0.1)$ & 7.3 & $(0.14)$ \\
\hline Mean airway pressure $\left(\mathrm{cm} \mathrm{H}_{2} \mathrm{O}\right)$ & 9.1 & $(1.3)$ & 8.8 & $(1.4)$ \\
\hline
\end{tabular}

$\mathrm{FIO}_{2}=$ fractional inspired oxygen concentration; $\mathrm{Po}_{2}=$ oxygen tension, $\mathrm{PCO}_{2}=$ carbon dioxide tension.

These data were recorded during the stabilising period (about $2-4$ hours) before the start of trial medication. No statistically significant differences were seen between the groups for any of the data.

Table 2 Clinical outcome during and after the dexamethasone treatment period

\begin{tabular}{ll}
\hline $\begin{array}{l}\text { Placebo } \\
\operatorname{group}(n=29)\end{array}$ & $\begin{array}{l}\text { Dexamethasone } \\
\operatorname{group}(n=34)\end{array}$ \\
\hline
\end{tabular}

No. weaning off mechanical ventilation from

the start of treatment

Day 1

Day 3

Day 7

Day 14

Day 21

During and after treatment period

0
2
4
4
1

Total no. weaned by 21

Incidence of sepsis

Deaths

Incidence of BPD

$11(37.9 \%)$

$20.7 \%(6 / 29)$

$20.7 \%(6 / 29)$

$31.0 \%(9 / 29)$

$20(58.8 \%)$

$14.3 \%(5 / 34)$

$20.6 \%(7 / 34)$

$14.3 \%(5 / 34)$

$\mathrm{BPD}=$ bronchopulmonary dysplasia

${ }^{\star} \mathrm{p}<0.05$ versus control and dexamethasone groups. All other comparisons were not significant.

SP-A $(10-1000 \mathrm{ng} / \mathrm{ml})$ and serial dilution of each tracheal aspirate sample. Absorbance was determined at $405 \mathrm{~nm}$. Correlation coefficients of the standard curve were generally $0.90-0.95$. Sample dilutions were adjusted to within the linear range.

The concentration of albumin was determined in undiluted tracheal aspirate fluid by computerised rate nephelometry (Beckman Instruments Inc, Fullerton, California, USA) with commercially available reagents (Kallestad Laboratories Inc, Austin, Texas, USA).

\section{CONCENTRATIONS OF CONSTITUENTS OF}

TRACHEAL ASPIRATE FLUID

To avoid errors resulting from the sampling procedure, the concentrations of lung constituents of tracheal aspirate fluids are usually expressed relative to the albumin concentrations. However, this is correct only when albumin concentrations in tracheal aspirates are constant during a certain period. In this study albumin concentrations were markedly affected by dexamethasone treatment, so we chose to express concentrations of all constituents of tracheal aspirate samples as a unit of weight per $\mathrm{ml}$ tracheal aspirate fluids. The suction technique was standardised as described above. The recovered volume of pulmonary effluent (approximately $0.75 \mathrm{ml}$ ) by a single tracheal suction did not change before and after dexamethasone treatment.
DATA ANALYSIS

The placebo/dexamethasone assignment code was broken two weeks after the last case study was completed. For tracheal aspirate data, values for a given day were the mean of three samples collected during that day and analysed separately. For clinical data related to pulmonary ventilation, values analysed were the highest measurements obtained during the testing period. All the data were expressed as mean (SD). Statistical significance for differences in results of gas exchange and biochemical data between treatment and control groups were evaluated by analysis of variance (ANOVA) for repeated measures and, when appropriate, multiple $t$ tests were used to justify the significance of the treatment effect at each time point. The Fisher's exact test was used to compare groups with respect to categorical variables. The relationship between pulmonary outcomes and surfactant proteins were analysed by linear regression. The log transformed data were used in the calculation of the Pearson correlation coefficients, a $\mathrm{p}$ value of $<0.05$ being considered significant.

\section{Results}

PATIENT ENROLLMENT AND CLINICAL OUTCOME During the one year study period 196 infants (including 55 transferred from other hospitals) who weighed 1000-1999 g were admitted to the neonatal intensive care unit, National Cheng-Kung University Medical Centre, 143 because of respiratory distress. All 70 of the infants who met the criteria were included in the study. Before the code was broken seven of the 70 infants were withdrawn from the study due to early onset of sepsis (within 12 hours of starting the study). The final number of infants included in the study was therefore 63 , with 29 in the placebo group and 34 in the dexamethasone treated group. Since many of the infants had their endotracheal tube removed as a result of clinical improvement within 14 days of age, the study period was limited to the first 14 days in both groups.

The clinical characteristics of the infants in the perinatal period are shown in table 1 . There were no significant differences in clinical and perinatal characteristics between the two groups before the time of admission to the study or in the use of prenatal glucocorticoid therapy (table 1). The difference in initial ventilatory settings between the groups was not significant at the time of entry. The mean postnatal age of the dexamethasone group at the time of the first dose was 9.2 (1.4) hours. During the treatment period $20(58.8 \%)$ of the infants in the dexamethasone group and 11 $(37.9 \%)$ in the control group were weaned from the mechanical ventilator $(\mathrm{p}<0.05$, table 2 ). Thirteen infants died during the study period, seven in the dexamethasone group (three aged less than 30 days) and six in the control group (all aged less than 30 days). The average duration of ventilatory support was similar in the two groups. There were no significant differences between the study groups with respect to the incidence of sepsis $(6 / 29$ versus $5 / 34)$ and other complications in 
the study period. The survival rate at 28 days after treatment without ventilatory support or bronchopulmonary dysplasia did not differ between the groups (table 2).

\section{GAS EXCHANGE}

Sequential changes in $\mathrm{FIO}_{2}, \mathrm{Po}_{2}, \mathrm{PcO}_{2}$, peak inspiratory pressure (PIP), and mean airway pressure (MAP) of mechanical ventilation during the study period are shown in fig 1 . Infants in the dexamethasone treated group had significantly lower $\mathrm{PCO}_{2}$ values on days 3 and 7, lower $\mathrm{FIO}_{2}$ on days 7 and 14, and lower MAP on days 3,7 , and 14 than infants in the control group, indicating an improvement in pulmonary status.

\section{SP-A AND SP-D CONCENTRATIONS IN TRACHEAL} ASPIRATES

The SP-A and SP-D assays used in this study were capable of detecting human SP-A levels of $10-1000 \mathrm{ng} / \mathrm{ml}$ and SP-D levels of $5-50$ $\mathrm{ng} / \mathrm{ml}$. The standard curves obtained using purified SP-A or SP-D within these ranges
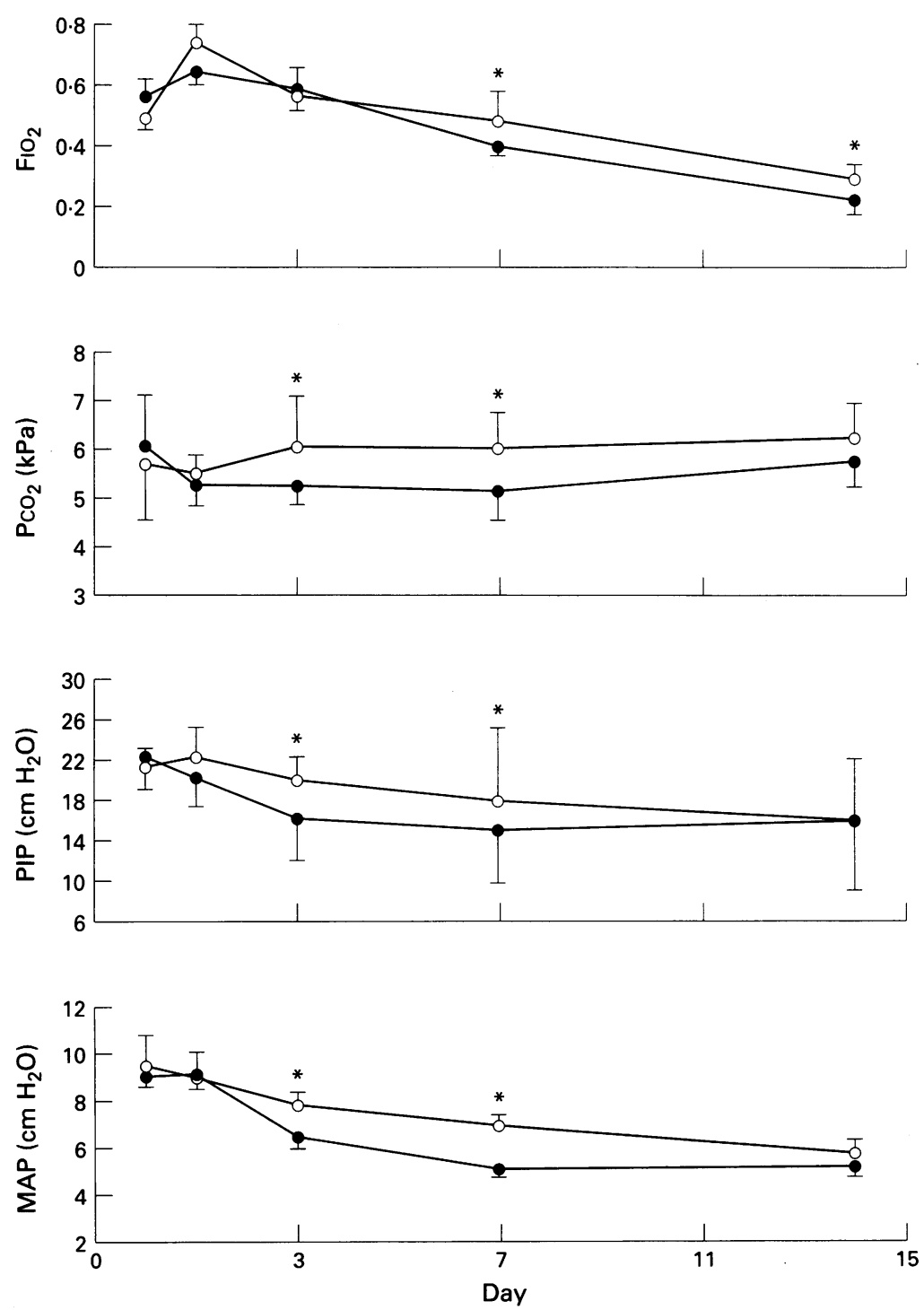

Figure 1 Sequential change in $\mathrm{FIO}_{2}$ (fraction of inspired oxygen), $\mathrm{PCO}_{2}$ (carbon dioxide tension), PIP (peak inspiratory pressure), and MAP (mean airway pressure) of mechanical ventilation in dexamethasone treated ( $(\bullet)$ and control groups $(0)$ during the study period. Number of subjects in dexamethasone and control groups at each stage of study as follows: before entry, 34 versus 29; after day 1, 33 versus 28; after day 3,25 versus 25; after day 7,15 versus 19; after day 14, 10 versus 13 . ${ }^{*} p<0.05$ compared with control group. were linear, and the dilutions of adult human tracheal aspirate samples consistently yielded curves parallel to the standard curve. Assay variations were assessed at four different concentrations of SP-D or SP-A. The intraassay coefficients of variation, calculated by comparing the results of 12 standard rows on one plate, were 0.15 for $31.3 \mathrm{ng} / \mathrm{ml}, 0.07$ for $62.5 \mathrm{ng} / \mathrm{ml}, 0.12$ for $125 \mathrm{ng} / \mathrm{ml}$, and 0.11 for $250 \mathrm{ng} / \mathrm{ml}$. The inter-assay coefficients of variation, calculated by comparing the results of 12 standard rows on eight plates assayed during a period of four months, were 0.26 for 31.3 $\mathrm{ng} / \mathrm{ml}, 0.21$ for $62.5 \mathrm{ng} / \mathrm{ml}, 0.19$ for $125 \mathrm{ng} / \mathrm{ml}$, and 0.15 for $250 \mathrm{ng} / \mathrm{ml}$.

In agreement with other reports, ${ }^{21}$ this study showed an increase in the mean SP-A and SP-D levels as the postnatal age increased during the first week, but this was not statistically significant because of a wide scatter of the data. A comparison of the treated (dexamethasone) and control groups showed that infants in the dexamethasone group had significantly higher SP-A levels on day 7 (35.84 (16.80) versus $20.58(12.48) \mu \mathrm{g} / \mathrm{ml}, \mathrm{p}<0.05)$ and day 14 (40.22 (24.20) versus 11.50 (9.24) $\mu \mathrm{g} / \mathrm{ml}$, $\mathrm{p}<0.01)$ than the control group. Similarly, SP-D levels were significantly higher in the dexamethasone group from days 3-14 after birth than in the control group (day 3: 254.5 $(124.8)$ versus $85.6(62.9) \mathrm{ng} / \mathrm{ml}, \mathrm{p}<0.01$; day 7: 297.9 (100.6) versus 108.2 (51.9) $\mathrm{ng} / \mathrm{ml}$, $\mathrm{p}<0.01$; day 14: 257.5 (36.8) versus 166.3 (49.8) $\mathrm{ng} / \mathrm{ml}, \mathrm{p}<0.05)$. However, values for albumin in the tracheal aspirate samples were significantly lower in the dexamethasone group than in the control group by day $3(74.52$ (25.1) versus 117.8 (25.4) $\mu \mathrm{g} / \mathrm{ml}, \mathrm{p}<0.05)$, day $7(73.8(29.4)$ versus $128.3(40.2) \mu \mathrm{g} / \mathrm{ml}$, $\mathrm{p}<0.05)$, and day 14 (39.5 (12.9) versus 96.4 (29.4) $\mu \mathrm{g} / \mathrm{ml}, \mathrm{p}<0.01$ ) (fig 2 ).

\section{SURFACTANT PROTEINS AND PULMONARY}

CONDITIONS

The relationship between pulmonary function (using $\mathrm{PCO}_{2}$ as the index) and surfactant protein levels in tracheal fluid was analysed by simple linear regression. During the study period we found a significant inverse correlation between $\mathrm{PCO}_{2}$ values and concentrations of SP-A $(r=-0.711, \mathrm{p}<0.01)$ but not SP-D $(r$ $=-0.289, \mathrm{p}=0.1)$. There was no significant relationship between SP-A and SP-D concentrations in the samples of tracheal aspirate during the study period $(r=0.241, \mathrm{p}=0.15)$ (fig $3)$.

\section{Discussion}

All the tracheal samples were collected by exactly the same procedure but it is difficult to establish if the material collected in each case is a true reflection of the alveolar contents. However, any SP-A or SP-D detected in the tracheal aspirates must have originated from alveolar type II cells (SP-A and SP-D) or Clara cells (SP-D). ${ }^{2}$ Although we have standardised our procedures during tracheal suctions, our results may also be biased by a dilution factor, depending on how much saline is reaspirated with tracheal suctioning and on the contribu- 

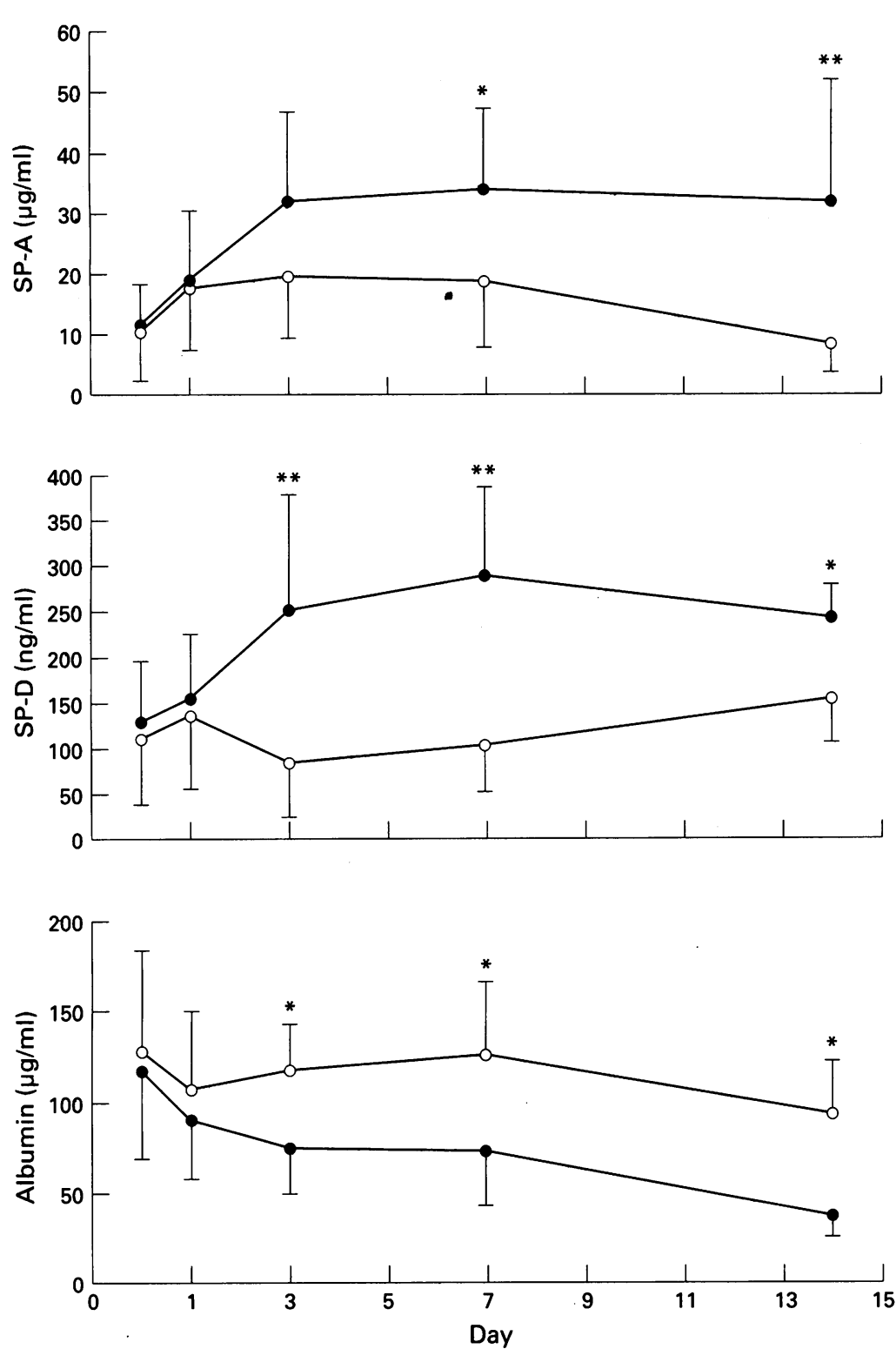

Figure 2 Mean (SD) concentration of SP-A, SP-D, and albumin in tracheal aspirate fluids from premature infants with RDS on days 0-14 after birth with $(\bullet)$ or without $(0)$ dexamethasone treatment. Number of subjects in dexamethasone and control groups at each stage of study as follows: before entry, 34 versus 29; after day 1, 33 versus 28; after day 3 , 25 versus 25 ; after day 7,15 versus 19 ; after day 14,10 versus $13 .{ }^{*} p<0.05, \star_{p}<0.01$ compared with control group. exclude samples in which only the instilled saline was recovered; however, the use of this ratio did not yield more information than using SP-A or SP-D concentrations alone. Chida et $a l^{1}$ reported similar findings using ratios of surfactant protein to albumin. No correlation was found between the concentration of SP-A in the tracheal samples and the volume of the samples recovered. Moreover, we found a significant decrease in the production of pulmonary albumin after treatment with dexamethasone (fig 2). This phenomenon is consistent with other reports that steroids may decrease general protein synthesis and turnover rate in the bronchoalveolar lavage fluid. ${ }^{22} 23$ For the purpose of this study only the results from the SP-A and SP-D concentration measurements expressed as units of weight per $\mathrm{ml}$ of tracheal aspirate fluids are therefore presented.

In this study we have shown that, after the early postnatal use of dexamethasone in infants with $\mathrm{RDS}$, not only is pulmonary function improved but also the levels of SP-A and SP-D in the tracheal aspirate fluid are significantly increased from day 7 in the case of SP-A, and from day 3 in the case of SP-D. These two components of human lung surfactantassociated proteins both show an increase in concentration, but at different times, in response to dexamethasone. Moreover, their levels did not correlate with each other during the study period. Both proteins remained low in the premature infants suffering from severe RDS on the first day of life, but the response of SP-D to dexamethasone treatment took place earlier than the response of SP-A, while the clinical improvement, as monitored by the $\mathrm{PCO}_{2}$ level, was correlated with the concentration of SP-A which was increased after one week of life. This is different from the normal pattern of spontaneous synthesis of surfactant proteins measured in amniotic fluid during the gestational period. ${ }^{20}$ In this period both SP-A and SP-D levels remain low until about 32 weeks of gestational age, after which SP-A levels increase rapidly while SP-D levels rise only slightly, resulting in a very high SP-A/SP-D ratio at term.

tion of extra-alveolar secretions. Calculating the ratio of SP-A to total protein helped to
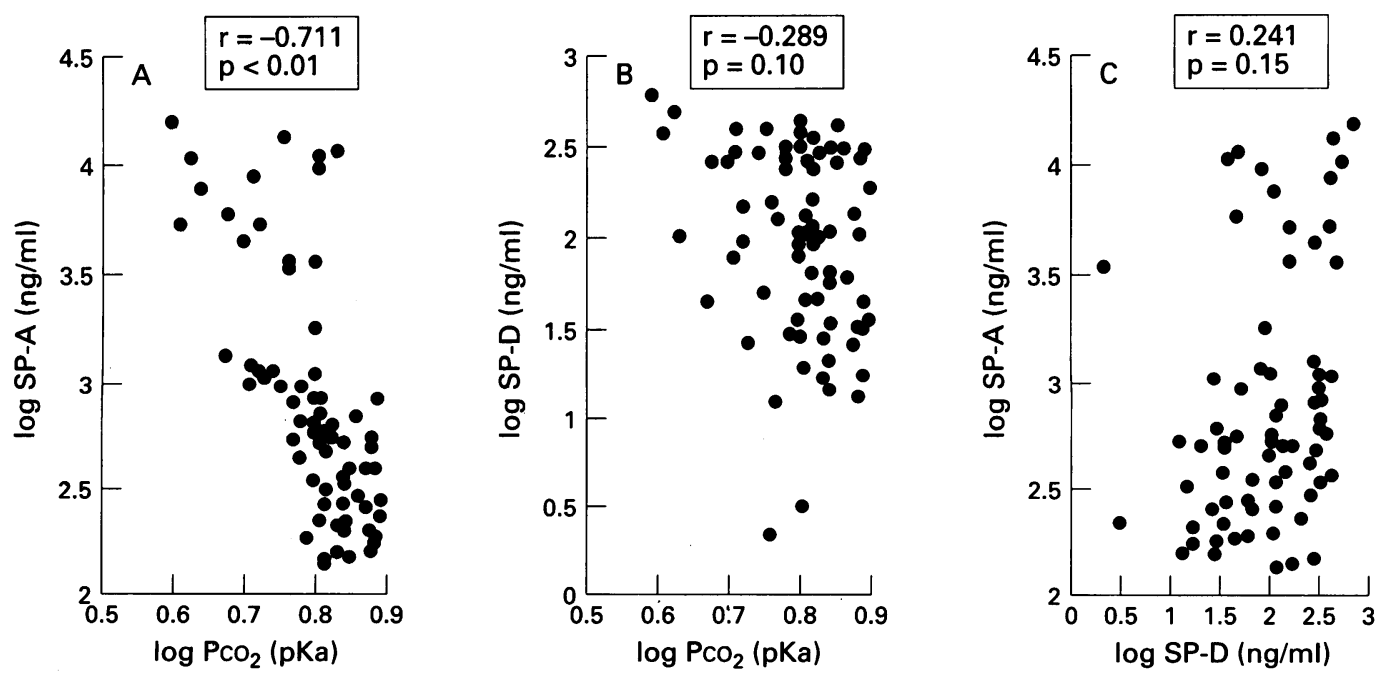

Figure 3 Relationships between log transformed $\mathrm{PCO}_{2}$ level and $(A) S P-A$ or $(B) S P-D$ concentrations in tracheal fluid during study period. (C) Relationship between log transformed SP-A and SP-D concentrations in each sample. 
Premature birth interrupts the normal pattern of lung development and frequently results in surfactant insufficiency and RDS. Infants with severe acute RDS have low or undetectable amounts of SP-A, SP-B, and SP-C. ${ }^{21}{ }^{24}$ Resolution of acute RDS is accompanied by an increase in surfactant protein levels. ${ }^{25}{ }^{26}$ Moya et a ${ }^{27}$ have recently reported that, among neonates with RDS, the initial concentration of SP-A in tracheal fluid had a significant inverse correlation with the degree of respiratory failure, but no such correlation was observed with tracheal fluid saturated with phosphatidylcholine. Moreover, Ashton et $a l^{8}$ have found that the clinical improvement in neonatal bronchopulmonary dysplasia resulting from dexamethasone treatment is not related to the change in surfactant phosphatidylcholine composition. The beneficial effect of dexamethasone treatment in infants with RDS may therefore be due to the increased synthesis of surfactant proteins rather than other components of the surfactant complex.

Dexamethasone has recently been used shortly after birth in infants with RDS to prevent lung injury and the development of bronchopulmonary dysplasia. ${ }^{15}$ Several mechanisms have been proposed for the action of dexamethasone. These include an increase in surfactant synthesis, stabilisation of cell and lysosomal membranes, decreases in inflammatory cell recruitment to the lung, inhibition of prostaglandins and leukotriene synthesis, and reduction of pulmonary oedema. ${ }^{22}{ }^{29}$ Although glucocorticoids have been shown to affect the rate of transcription of both SP-A and SP-D in animals and fetal lung explant culture, the molecular aspects of the activation of the promoter elements of the genes encoding these proteins, after triggering of steroid receptors, have not been fully elucidated. ${ }^{19}{ }^{30}$ The regulation of expression of surfactant proteins by glucocorticoids is extremely complex and varies as a function of dose, developmental age, and species. ${ }^{4}$ Postnatal administration of dexamethasone to rats resulted in a dosedependent increase in both newly synthesised and secreted SP-A as well as a modest increase in mRNA of SP-A at all ages, but appeared to be more effective at earlier postnatal ages. ${ }^{31}$ In the present study the concentrations of both SP-A and SP-D increased postnatally after early use of dexamethasone, concurrent with the resolution of acute respiratory distress and improvement in pulmonary ventilation. However, we are only able to demonstrate a weak inverse correlation between the $\mathrm{PCO}_{2}$ value and SP-A concentration. A more complex mechanism may therefore be present. In agreement with other reports, ${ }^{22} 2932$ our study also suggested that the anti-inflammatory action of dexamethasone, as indicated by the decreased levels of albumin in tracheal aspirates, may also play a part in the improvement of lung function.

The use of dexamethasone in the treatment of premature infants with RDS is not without hazard, the risk of infections and decrease in somatic growth being of major concern. However, SP-A and SP-D have been shown to enhance chemotaxis and phagocytosis of alveolar macrophages, ${ }^{12334}$ and increased SP-A levels in tracheal aspirate fluids have been found in infants who have survived from RDS. ${ }^{25}{ }^{26}$ We found no increase in the episodes of sepsis following treatment with dexamethasone in this study or in our previous report. ${ }^{15}$ Further studies on the pathophysiological role of surfactant-associated proteins are needed to construct a rational protocol of treatment for $\mathrm{RDS}$ and bronchopulmonary dysplasia in premature infants.

JY Wang is studying at University of Oxford supported by a scholarship from Minister of Education, Taiwan, Republic of China. We thank Dr J Lu (MRC Immunochemistry Unit, Oxford) for anti-human SP-D antibody and $\mathrm{Dr} S$ Thiel (Aarhus, Denmark) for anti-human SP-A antibody. We are grateful to the medical and nursing staffs of the neonatal intengrateful to the medical and nursing staffs of the neonatal intensive care unit, National Cheng-Kung University Medical
Center, for their cooperation and tolerance. This study is Center, for their cooperation and tolerance. This study is
supported in part by grants NSC $80-0412-\mathrm{B} 006-27$ and NSC 80-0412-B006-47 from National Science Councils, and by grant DOH 82-HR-C17 from the National Institute of Health Research, Department of Health, Taiwan, Republic of China.

1 Farrell PM, Avery MA. Hyaline membrane disease. Am Rev Respir Dis 1975;111:657-88.

2 Johansson J, Curstedt T, Robertson B. The proteins of the surfactant system. Eur Respir ₹ 1994;7:372-91.

$3 \mathrm{Yu} \mathrm{SH}$, Possmayer F. Role of pulmonary surfactantassociated proteins in the surface-active property of phospholipid mixtures. Biochim Biophys Acta 1990;1046:233 41 .

4 Weaver TE, Whitsett JA. Function and regulation of expression of pulmonary surfactant-associated proteins. Biochem f 1991;173:249-64.

5 Suzuki Y, Fujita Y, Kogishi K. Reconstitution of tubular myelin from synthetic lipids and proteins associated with pig pulmonary surfactant. Am Rev Respir Dis 1989 140:75-81.

6 Rice WR, Ross GF, Singleton FM, Dingle S, Whitsett JA Surfactant-associated protein inhibits phospholipid secretion from type II cells. $\mathcal{F}$ Appl Physiol 1987;63:692-8.

7 Persson A, Chang D, Rust K, Moxley M, Longmore W, Crouch E. Purification and biochemical characterization of CP4 (SP-D), a collagenous surfactant-associated protein. Biochemistry 1989;28:6361 1-67.

$8 \mathrm{Lu} \mathrm{JH}$, Willis AC, Reid KBM. Purification, characterization and cDNA cloning of human lung surfactant protein D. Biochem $\mathcal{f}$ 1992;284:795-802.

9 Lim BL, Wang JY, Holmskov U, Hoppe HJ, Reid KBM Expression of the carbohydrate recognition domain of lung surfactant protein $\mathrm{D}$ and demonstration of the binding to lipopolysaccharides of Gram-negative bacteria. Biochem Biophys Res Commun 1994;202:1674-80.

10 Wright JR, Youmans DC. Pulmonary surfactant protein A stimulates chemotaxis of alveolar macrophage. $A m \mathcal{F}$ Physiol 1993;264:L338-44.

11 Holmskov U, Malhotra R, Sim RB, Jensenius JC. Collectins: collagenous $\mathrm{C}$-type lectins of the innate immune dense system. Immunol Today 1994;15:67-74.

12 Van Iwaarden JF. Surfactant and pulmonary defense system. In: Robertson B, Van Golde, LMG, Batenburg JJ, eds. Pulmonary surfactant: from molecular biology to clinical practice. Amsterdam: Elsevier Science, 1992:215-29.

13 Hong SCL, Levine I. Inhibition of arachidonic acid release from cells as the biochemical action of anti-inflammatory corticosteroids. Proc Natl Acad Sci USA 1976;73:1730-4.

14 Mammal MC, Johnson DE, Green TP, Thompson TR Controlled trial of dexamethasone in respiratory dependent infants with bronchopulmonary dysplasia. Lancet 1983;i:1356-8.

15 Yeh TF, Torre JA, Rastogi A, Anyebuno MA, Pildes RS Early postnatal dexamethasone therapy in premature infants with severe respiratory distress syndrome: double-blind, controlled study. F Pediatr 1990;117:273-82.

16 Sanders RJ, Cox C, Phelps DL, Sinkin RA. Two doses of early intravenous dexamethasone for the prevention of bronchopulmonary dysplasia in babies with respirator distress syndrome. Pediatr Res 1994;36:122-8.

17 Iannuzzi DM, Ertsey R, Ballard PL. Biphasic glucocorticoid regulation of pulmonary SP-A: characterization of inhibitory process. Am $\mathcal{F}$ Physiol 1993;264:L236-44.

18 Deterding RR, Shimizu H, Fisher JH, Shannon JM. Regulation of surfactant protein $\mathrm{D}$ expression by glucocorticoids in vitro and in vivo. Am $\mathcal{f}$ Respir Cell Mol Biol 1994;10:30-7.

19 Fraslon C, Batenburg JJ. Pre-translational regulation of lipid synthesizing enzymes and surfactant protein in fetal rat
lung in explant culture. FEBS Lett 1993;325:285-90.

20 Miyamura K, Malhotra R, Hoppe HJ, Reid KBM, Phizackerley PJR, Macpherson P, et al. Surfactant protein A SP-A) and D (SP-D): levels in human amniotic fluid and localization in the fetal membranes. Biochim Biophys Acta
1994;1210:303-7. 
21 Chida S, Phelps D, Cordle C, Soll R, Floros J, Taeusch HW. Surfactant-associated proteins in tracheal aspirates of infants with respiratory distress syndrome after surfactant therapy. Am Rev Respir Dis 1988;137:943-7.

22 Groneck P, Reuss D, Gotze-Speer B, Speer CP. Effects of dexamethasone on chemotactic activity and inflammatory dexamethasone on chemotactic activity and inflammatory mediators in tracheobronchial aspirates of preterm infants at risk for chronic lung disease. F Pediatr 1993;122:938-44.
Fussell JC, Kelly FJ. Effects of dexamethasone on lung protein turnover. Biochem $\mathcal{f}$ 1991;273:93-7.

24 DeMello DE, Phelps DS, Patel G, Floros J, Lagunoff D. Expression of the $35 \mathrm{kDa}$ and low molecular weight surfactant-associated proteins in the lungs of infants dying with respiratory syndrome. Am $\mathcal{F}$ Pathol 1988;134:128593.

25 Gerdes JS, Abbasi S, Karp K, Hull W, Whitsett JA Surfactant protein-A in bronchoalveolar lavage fluid from neonates with RDS on conventional and high-frequency neonates with RDS on conventional and high-frequency

26 Stevens PA, Schadow B, Bartholain S, Segerer H, Obladen $M$. Surfactant protein $A$ in the course of respiratory distress syndrome. Eur F Paediatr 1992;151:596-600.

27 Moya FR, Montes HF, Thomas VL, Mouzinho AM, Smith JF, Rosenfeld CR. Surfactant protein A and saturated phosphatidylcholine in respiratory distress syndrome. $\mathrm{Am}$ $\mathcal{F}$ Respir Crit Care Med 1994;150:1672-7.
28 Ashton MR, Postle AD, Smith DE, Hall MA. Surfactant phosphatidylcholine composition during dexamethasone treatment in chronic lung disease. Arch Dis Child 1994;71:F114-7.

29 Voder MC, Chua R, Tepper R. Effects of dexamethasone on pulmonary inflammation and pulmonary function of ventilator-dependent infants with bronchopulmonary dysventilator-dependent infants with bronchopulm
plasia. Am Rev Respir Dis 1991;143:1044-8.

30 Ogasawara Y, Kuroki Y, Tsuzuki A, Ueda S, Misaki H, Akino T. Pre- and postnatal stimulation of pulmonary surfactant protein $\mathrm{D}$ by in vivo dexamethasone treatment of rats. Life Sci 1992;50:1761-7.

31 Floros J, Phelps DS, Harding HP, Church S, Ware J. Postnatal stimulation of rat surfactant protein A synthesis by dexamethasone. Am f Physiol 1989;257:L137-43.

32 Gerdes JS, Harris MC, Polin RA. Effect of dexamethasone and indomethacin on elastase, $\alpha 1$-proteinase inhibitor, and fibronectin in bronchoalveolar lavage fluid from neonate. $₹$ Pediatr 1988;113:727-31.

33 Van Iwaarden F, Welmers B, Verhoef J, Haagsman HP, Van Golde LMG. Pulmonary surfactant protein A enhances the host defense mechanism of rat alveolar macrophages. Am 7 Respir Cell Mol Biol 1990;2:91-8.

34 Wright JR, Yumans DC. Pulmonary surfactant protein A stimulates chemotaxis of alveolar macrophage. $\mathrm{Am} \mathcal{f}$ Physiol 1993;264:L338-44. 